\title{
Analysis of drought characteristics for improved understanding of a water resource system
}

\author{
AMY T. LENNARD, NEIL MACDONALD \& JANET HOOKE \\ School of Environmental Sciences, University of Liverpool, Liverpool L69 7ZT, UK \\ a.lennard@liv.ac.uk
}

\begin{abstract}
Droughts are a reoccurring feature of the UK climate; recent drought events (2004-2006 and 2010-2012) have highlighted the UK's continued vulnerability to this hazard. There is a need for further understanding of extreme events, particularly from a water resource perspective. A number of drought indices are available, which can help to improve our understanding of drought characteristics such as frequency, severity and duration. However, at present little of this is applied to water resource management in the water supply sector. Improved understanding of drought characteristics using indices can inform water resource management plans and enhance future drought resilience. This study applies the standardised precipitation index (SPI) to a series of rainfall records (1962-2012) across the water supply region of a single utility provider. Key droughts within this period are analysed to develop an understanding of the meteorological characteristics that lead to, exist during and terminate drought events. The results of this analysis highlight how drought severity and duration can vary across a small-scale water supply region, indicating that the spatial coherence of drought events cannot be assumed.
\end{abstract}

Key words drought; water resource management; standardised precipitation index

\section{INTRODUCTION}

Droughts are complex natural hazards with multifaceted effects that can cause significant socioeconomic and environmental impacts. As a recurrent feature of the European climate, there have been several drought events during the 20th Century (Lloyd-Hughes and Saunders 2002). It is estimated that the cost of drought in Europe in the past 30 years was $€ 100$ billon (EC 2007). Recent drought events (2004-2006 and 2010-2012) have highlighted the UK's continued vulnerability to this hazard. Recent events identify the need for continued drought research across the UK. Brown et al. (2010) identify an increased understanding of extreme events (droughts and flooding) as a key research priority within the UK water sector.

UK drought research has predominantly focused on climate models and prediction, with little use of drought indices for event characterisation, ignoring the wealth of long climate data series available (Todd et al. 2013). Past research has been focused at European or national scales rather than at a regional scale, with large-scale studies often failing to capture the spatial variability that a smaller, regional study could provide (Hannaford et al. 2010). Regional-scale studies are more beneficial for water resource management, as shown by Phillips and McGregor (1998) and Fowler and Kilsby (2002) who use a regionalised approach to characterise drought events. Panu and Sharma (2002) identified several areas of future research focus within droughts; these included the importance of drought indices and recognition of regional variability. Although, there have been several drought studies in the UK, few of these have applied the Standardised Precipitation Index (SPI). The SPI developed by McKee et al. (1993), is a widely applied meteorological drought index that quantifies precipitation deficits. At present, the SPI is underutilised for drought management planning and monitoring in the UK by both government agencies and the water supply sector. In this study, precipitation data from locations across a single water sector supply region are analysed using the SPI to determine drought structures, with the aim of improving understanding of drought characteristics for water resource management.

\section{Study area}

The Severn Trent Water supply region is approximately $21000 \mathrm{~km}^{2}$ spanning central England and mid-Wales. The study area includes a variety of landscapes with uplands over $400 \mathrm{~m}$ a.s.l. in the north and west; the central plateau region is at between 100 to $250 \mathrm{~m}$ a.s.l. and the south and east of the region has lower lying relief. Considerable variation in rainfall exists across the region, ranging from $1800 \mathrm{~mm}$ in the Welsh uplands to $650 \mathrm{~mm}$ in the southeast of the area (Met Office 
2013). Severn Trent Water supply approximately 7.4 million people in the region; supplies are sourced from reservoirs, river abstractions and groundwater, with each source contributing approximately $33 \%$ to the total supply.

\section{METHODS AND MATERIALS}

\section{Data}

Daily precipitation data were collected from 14 sites (Fig. 1) across the study region from 19622012, of which seven series are available for the period 1900-2012 providing a longer-temporal context. However, these long series are not within the scope of this paper. The time period 19622012 was selected for two reasons: (i) The period provides a sufficient record length to ensure meaningful SPI calculations; and (ii) the start of the 1960s witnessed an increase in precipitation recording across the region. The raingauges selected are at a variety of altitudes (17-268 $\mathrm{m}$ a.s.l) reflecting the varying climatological conditions of the study area. It must be noted that site $\mathrm{K}$ (Fig. 1) lies outside of the water utility provider's boundary, but a significant reservoir system that provides supplies to the study region is located here. Precipitation data were obtained from the British Atmospheric Data Centre (www.badc.nerc.ac.uk). The site selection process included checks for percentage of data missing (sites with more than $20 \%$ of data missing were rejected) and identification of suitable weather stations to provide missing data. Gaps in the records were filled using linear regression techniques with data from additional suitable nearby weather stations (all weather stations used for missing data were within $10 \mathrm{~km}$ of the selected sites), a detailed description of this method can be found in Macdonald et al. (2008); these were checked for homogeneity, trend and randomness.

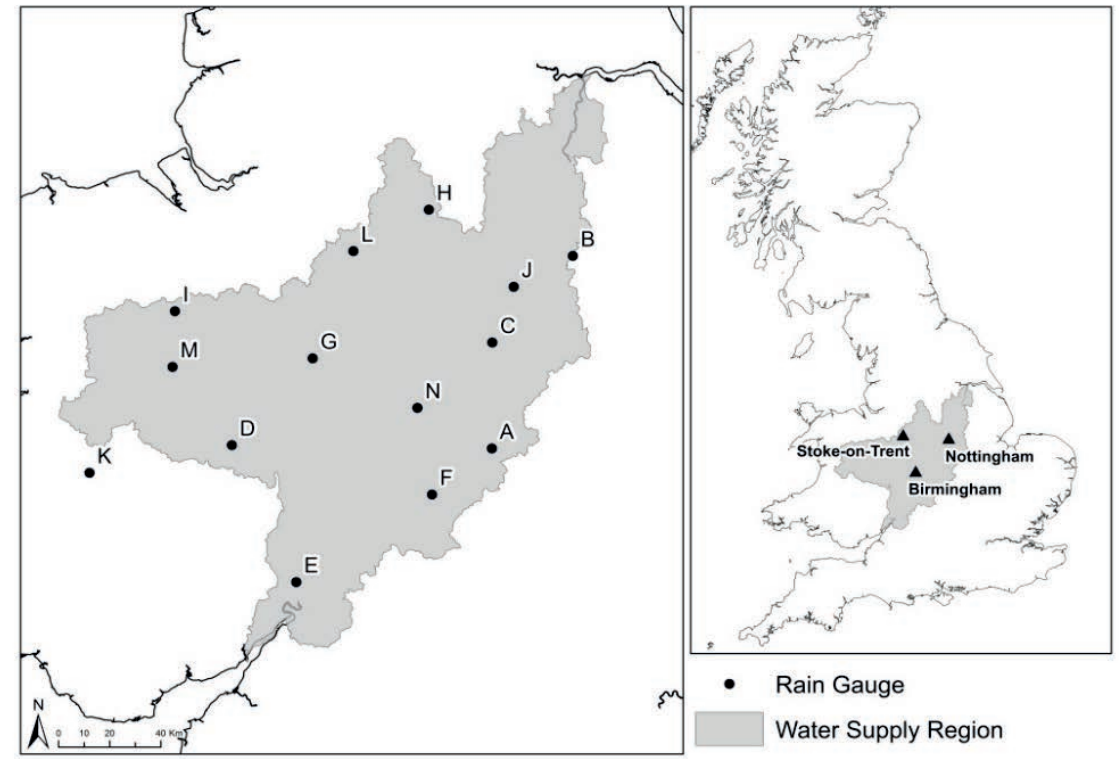

Fig. 1 Study area and location of raingauges.

\section{Standardised precipitation index}

The standardised precipitation index (SPI) is a commonly used meteorological drought index to quantify rainfall deficits based on the probability of precipitation for multiple time scales. Commonly used time scales are 1-, 3-, 6-, 12- and 24-month. These time scales are selected to reflect the impact of drought on various water resources; e.g. soil moisture responds at a faster rate to rainfall deficits than groundwater. SPI values are a dimensionless unit usually ranging from 2 to -2 (see Lloyd-Hughes and Saunders (2002) for a detailed review of the SPI). SPI values and corresponding drought classification are shown in Table 1. A drought event is assumed to occur when the SPI value is smaller or equals -1.00 ; drought termination is assumed when the SPI 
exceeds or equals 0 . The standardised nature of the SPI allows for the comparison of drought conditions at different locations. Calculations are based on long-term rainfall records for a chosen time period. The SPI calculation was applied to rainfall data for each of the 14 sites at a 12 month timescale for the period 1962-2012. This study focuses on the SPI-12 month scale as this is appropriate when considering the impact of drought on surface waters (Mishra and Singh 2010).

Table 1 Standardised precipitation index classifications (McKee et al. 1993).

\begin{tabular}{llll}
\hline SPI value & Classification & SPI value & Classification \\
\hline 2.00 or more & Extremely wet & -1.00 to -1.49 & Moderate drought \\
1.50 to 1.99 & Very wet & -1.50 to -1.99 & Severe drought \\
1.00 to 1.49 & Moderately wet & -2.00 or less & Extreme drought \\
-0.99 to 0.99 & Near normal & & \\
\hline
\end{tabular}

\section{RESULTS AND DISCUSSION}

The SPI series for each site from 1962-2012 are presented in Fig. 2. Three multi-year droughts can be identified: 1975-1976, 1995-1996 and 2010-2012. These drought events were investigated further to determine the key characteristics in their formation.

\section{Drought characteristics}

1975-1976 Across the region drought onset occurred in January 1975 at sites D, G, M and N in the west of the region. Onset at the remaining sites occurred during the summer months of June, July and August. Site K was the final site to reach drought conditions in September 1975. Drought duration was variable across the region, ranging from 17 months (E) to 26 months (M). Peak severity occurred in July (A, C, F and N) and August 1976 (B, D, F, G, H, I, J, K, L, and M); from September 1976 drought conditions become less extreme. Termination of drought conditions was also variable across the region (Fig. 3(a)). Across much of the region drought termination was reached by January 1977; however, sites L and K waited until April and July 1977, respectively. The drought was classified as extreme across the region, with severities ranging from -2.59 to -3.42 .

1995-1997 Onset varied across the region from March 1995 (N) to December 1995 (K); by September 1995 all sites with the exception of $\mathrm{K}$ were in drought. Event duration ranged from 24 months (B) to 35 months (J; Fig. 3(b)). The drought continued through until 1997; by April 1997 the severity of the drought had begun to reduce at all sites. Rainfall had returned to "normal" conditions by December 1997 with the exception of site J, where the drought terminated in March 1998. Peak severity ranged from $-1.58(\mathrm{~K})$ to $-2.96(\mathrm{H})$.

2010-2012 Drought onset was highly variable across the region ranging from January 2010 ( $\mathrm{G}$ and N) to March 2011. Most sites entered drought conditions in 2010 (Fig 3(c)) with the exceptions of sites A, J and L; onset at these sites occurred between January and March 2011. Drought duration was also highly variable across the region, ranging from 8 months $(\mathrm{L})$ to 31 months (G, K, I and N). The sites reached peak severity between October (C, D, E, F, G and M) and November (A, B, H, I, J, K, L and N) 2011. By March 2012 the drought was becoming less severe across the region. Event termination ranged from April (J and B) to November (K) 2012. Peak drought severity ranged from $-1.31(\mathrm{~L})$ to $-3.38(\mathrm{~N})$.

\section{Spatial variability}

Pearson's correlation coefficient has been used to identify the significance of relationships between the SPI values. There are significant correlations between all the sites at the 0.01 level (Table 2); this is expected due to the close proximity of the sites in the study area. The highest correlation coefficient is 0.91 for sites $\mathrm{B}$ and $\mathrm{C}$, the lowest 0.46 between sites $\mathrm{J}$ and $\mathrm{K}$. The variation in inter-site correlation is a function of distance between the sites. The relationship between site $\mathrm{K}$ and all other sites is consistently the weakest; the largest correlation coefficient is 0.71 between site $\mathrm{K}$ and $\mathrm{M}$. The weaker relationships between site $\mathrm{K}$ and other sites suggest there 

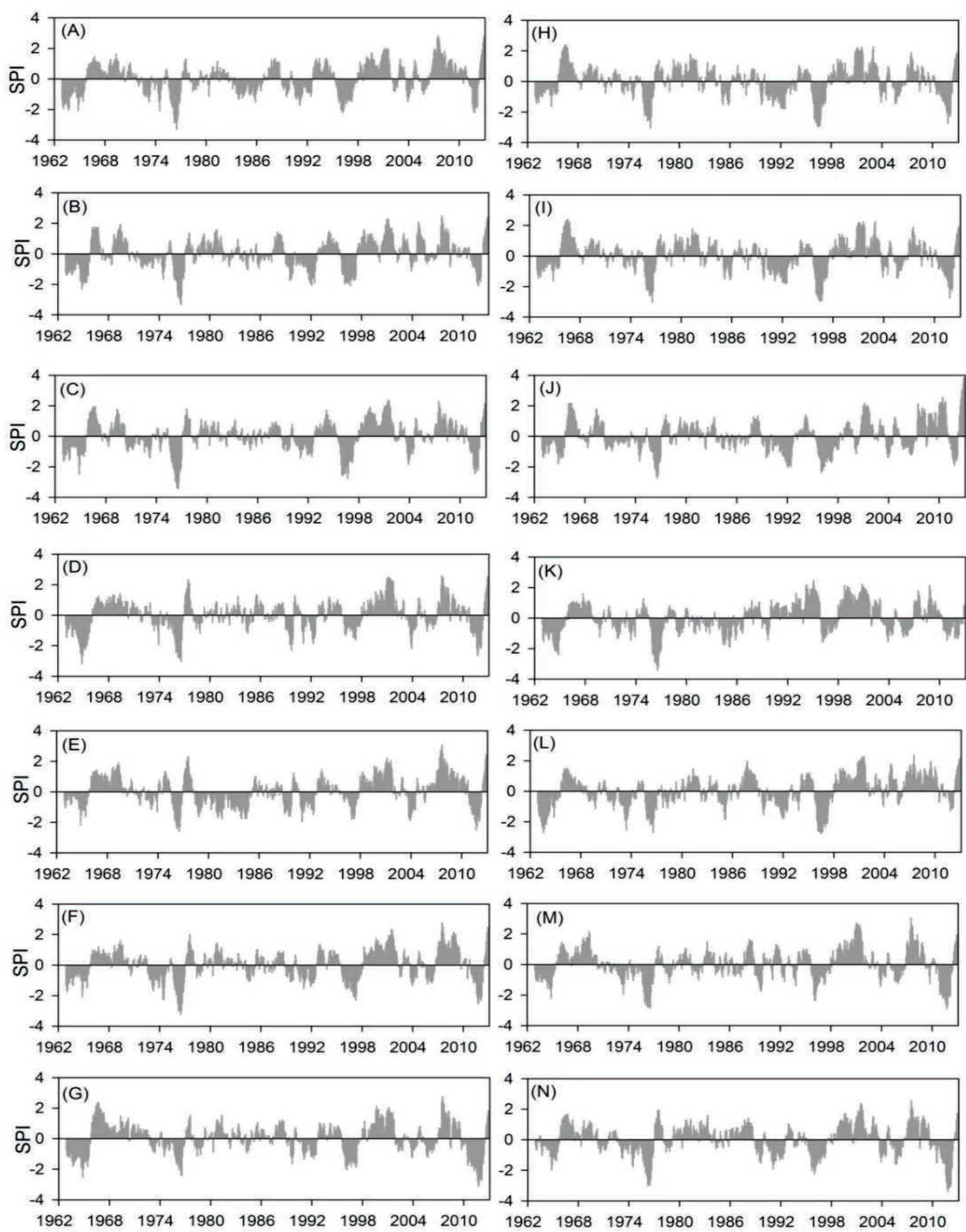

Fig. 2 SPI-12 month series (1962-2012) for sites A-N.

is a distinct climatology for the site and surrounding upland areas in the west of the supply region. Examination of the correlation coefficient analysis suggests there are divisions within the drought climatology of the region, with sites in the west (D, E, G, I, K and M) showing strong inter-site relationships, whilst the same is also observed for sites in the east of the region (A, B, C, F, H, J, L and $\mathrm{N}$ ). However, these results are preliminary, with further analysis required to fully establish whether there are distinct sub-regional drought climatologies. 
Although there is considerable similarity between sites, there is variability in the drought characteristics between sites, with implications for water resource management, particularly drought duration and magnitude. The variability may alter recovery times of reservoirs, e.g. during the 1975-1976 drought, site K located next to a strategically important reservoir system lagged 8 months behind drought termination at site D, shown in Fig 3. This may indicate that spatial coherence of drought events cannot be assumed, particularly when focusing on the implications of drought on water resources.
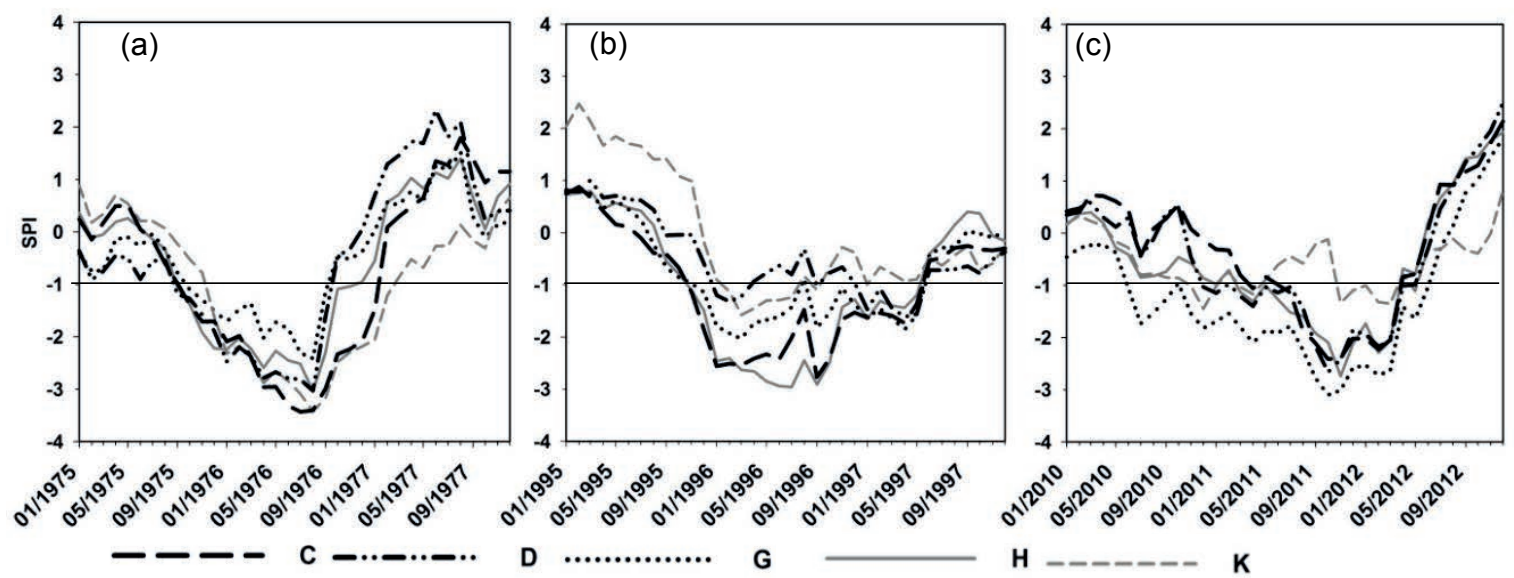

Fig. 2 SPI series for (a) 1975-1976, (b) 1995-1997 and (c) 2010-2012 events for five sites.

Table 2 Cross correlation of SPI-12 month values between sites (all significant at the 0.01 level).

\begin{tabular}{lrrrrrrrrrrrrrr}
\hline Site & $\mathrm{A}$ & $\mathrm{B}$ & $\mathrm{C}$ & $\mathrm{D}$ & $\mathrm{E}$ & $\mathrm{F}$ & $\mathrm{G}$ & $\mathrm{H}$ & $\mathrm{I}$ & $\mathrm{J}$ & $\mathrm{K}$ & $\mathrm{L}$ & $\mathrm{M}$ & $\mathrm{N}$ \\
\hline $\mathrm{A}$ & & .86 & .89 & .79 & .78 & .90 & .82 & .78 & .80 & .80 & .65 & .79 & .78 & .82 \\
$\mathrm{~B}$ & .86 & & .91 & .78 & .68 & .82 & .79 & .82 & .80 & .86 & .58 & .76 & .76 & .79 \\
$\mathrm{C}$ & .89 & .91 & & .81 & .75 & .89 & .83 & .85 & .83 & .86 & .67 & .77 & .81 & .87 \\
$\mathrm{D}$ & .79 & .78 & .81 & & .83 & .86 & .87 & .72 & .86 & .71 & .66 & .67 & .84 & .82 \\
$\mathrm{E}$ & .78 & .68 & .75 & .83 & & .79 & .74 & .58 & .76 & .62 & .62 & .58 & .72 & .69 \\
$\mathrm{~F}$ & .90 & .82 & .89 & .86 & .79 & & .86 & .78 & .82 & .77 & .65 & .75 & .83 & .89 \\
$\mathrm{G}$ & .82 & .79 & .83 & .87 & .74 & .86 & & .79 & .83 & .68 & .62 & .71 & .83 & .87 \\
$\mathrm{H}$ & .78 & .82 & .85 & .72 & .58 & .78 & .79 & & .79 & .77 & .57 & .78 & .74 & .83 \\
$\mathrm{I}$ & .80 & .80 & .83 & .86 & .76 & .82 & .83 & .79 & & .68 & .67 & .75 & .87 & .79 \\
$\mathrm{~J}$ & .80 & .86 & .86 & .71 & .62 & .77 & .68 & .77 & .68 & & .46 & .71 & .67 & .73 \\
$\mathrm{~K}$ & .65 & .58 & .67 & .66 & .62 & .65 & .62 & .57 & .67 & .46 & & .66 & .71 & .54 \\
$\mathrm{~L}$ & .79 & .76 & .77 & .67 & .58 & .75 & .71 & .78 & .75 & .71 & .66 & & .69 & .68 \\
$\mathrm{M}$ & .78 & .76 & .81 & .84 & .72 & .83 & .83 & .74 & .87 & .67 & .71 & .69 & & .80 \\
$\mathrm{~N}$ & .82 & .79 & .87 & .82 & .69 & .89 & .87 & .83 & .79 & .73 & .54 & .68 & .80 & \\
\hline
\end{tabular}

\section{Implications for water resource management}

Reconstructing drought series for past events improves our understanding of drought characteristics for a region, providing improved understanding of drought characteristics, propagation of drought through a water resource system and possible insights into the impact of climate change on future droughts. However, analysis of meteorological drought characteristics is insufficient to gain a full understanding of drought characteristics and the implications for water resource management. It would also be beneficial to utilise long series, particularly precipitation data (>100 years) in the UK, to place recent events into a longer term context (Marsh et al. 2007). Future work will include analysis of long precipitation series. It is necessary to consider stream flow, groundwater and reservoir data to develop a more complete understanding of future drought risks, with few studies having previously considered all available data sources. 


\section{CONCLUSION}

Recent drought events in the UK have highlighted the need for continued research, including the impact of hydrological extremes within the water resource and management sector. The SPI has rarely been applied in the UK, with previous research often focused on modelling approaches, ignoring the use of drought indices and long data series available for analysis. This study applies the SPI across 14 sites in a single UK water resource region to characterise drought events from 1962-2012. During this period, three multi-year droughts were identified: 1975-1976, 1995-1997 and 2010-2012. The characteristics of these events have been analysed to investigate spatial variability across the water supply region. Event onset, duration and termination are particularly variable. Understanding the features of past key drought events may be used to inform future management decisions. However, the use of longer precipitation records ( $>100$ years) that contain periods of drought during the early 1900s, 1920s and 1930s would provide important longtemporal context in terms of drought severity, frequency and duration.

\section{REFERENCES}

Brown, L. E. et al. (2010) Priority water research questions as determined by UK practitioners and policy makers. Sci. Total Environ. 409(2), 256-66.

European Commission, (2007) Communication addressing the challenge of water scarcity and droughts in the European Union, (COM (2007) 414)

Fowler, H. J. and Kilsby, C. G. (2002) A weather-type approach to analysing water resource drought in the Yorkshire region from 1881 to 1998. J. Hydrol. 262(1-4), 177-192.

Hannaford, J., et al. (2011) Examining the large scale spatial coherence of European drought using regional indicators of precipitation and streamflow deficit. Hydrol. Processes 25(7), 1146-1162.

Lloyd-Hughes, B, and Saunders, M. A. (2002) A drought climatology for Europe. Int. J. Climatol., 22, 1571-1592.

Marsh, T, Cole, G. and Wilby, R. (2007) Major droughts in England and Wales, 1800-2006. Weather 62(4), 87-93

Macdonald, N., Phillip, I. D and Thorpe, J. (2008) Reconstruction of long-term precipitation records for Edinburgh: An examination of the mechanisms responsible for temporal variability in precipitation. Theor. and Appl. Climatol. 92(3-4), $141-154$.

McKee, T. B., Doesken, N. J. and Kleist, J. (1993) The relationship of drought frequency and duration to time scales. In: Eighth Conference on Applied Climatology, 17-22 January 1993, Anaheim, California. 17-22.

Met Office (2013) Regional Climate. Available from: http://www.metoffice.gov.uk/climate/uk/mi/ (accessed: 01/10/2013).

Mishra, A. K. and Singh, V.P. (2010) A review of drought concepts. J. Hydrol. 391, 202-216.

Panu, U. S. and Sharma, T. C. (2002) Challenges in drought research: some perspectives and future directions. Hydrol. Sci. J. 47, S19-S30.

Phillips, I. D. and McGregor, G. R. (1998) The utility of a drought index for assessing the drought hazard in Devon and Cornwall, South West England. Meteorol. Appl. 5, 359-372.

Todd, B., et al. (2013) Increasing drought severity and duration - a historical climate reconstruction for SE England (16972010). Climatic Change, doi:10.1007/s10584-013-0970-6. 